\title{
A New Synthetic Approach For Nonlinear Optical Chromophores Possessing Enhanced Thermal Stability
}

\author{
Ching-Fong Shu*, Wen-Jen Tsai \\ Department of Applied Chemistry, National Chiao Tung University \\ Hsin-Chu, Taiwan, ROC \\ Alex K-Y. Jen* \\ Optical Materials Division, ROI Technology \\ 2000 Cornwall Road, Monmouth Junction, NJ 08852 USA
}

\begin{abstract}
A synthetic strategy for NLO chromophores containing cyclic-locked, conjugated triene segment has been developed. The incorporation of the ethylenic bonds into a 6 -membered ring resulted in enhanced thermal stabilities of chromophores. Copyright $(\mathcal{C} 1996$ Elsevier Science Ltd
\end{abstract}

Dipolar chromophores of the form D- $\pi-A$, where $D(A)$ is an electron donor (acceptor) group and $\pi$ is an electron-conjugated bridge linking $\mathrm{D} / \mathrm{A}$ moieties, possessing large molecular second-order nonlinearity $(\beta \mu)$ are of current interest because of their potential applications in electro-optic devices. ${ }^{1}$ Structureproperty relationships that have been established indicate that $\beta \mu$ values increases with increasing donor and acceptor strengths and with increasing $\pi$-conjugation length. ${ }^{2}$ Polyenes are often used as $\pi$-conjugated units to optimize $\beta \mu$. Unhampered by aromaticity, polyenes provide the most effective pathway for efficient charge delocalization between donor and acceptor groups, since the neutral and charge-separated states consist of similar $\pi$-systems of alternating single and double bonds. ${ }^{3}$ Chromophores with extended polyene chains as $\pi$-conjugated units can have unprecedented nonlinearities. ${ }^{4}$ However, simple polyenes suffer from the disadvantage of not being sufficiently thermally stable, making them unsuitable for device applications, where chromophores with thermal stabilities exceeding $200^{\circ} \mathrm{C}$ are often required in order to survive the material processing and device fabrication steps. 1,5 In this study, we present a new synthetic strategy for developing NLO chromophores containing conjugated triene segment in which part of the ethylenic bonds have been incorporated into a 6-membered ring system, leading to dramatically enhanced thermal stabilities as compared with simple triene analogues.

There are examples of near infrared absorbing dyes which were improved their photo-stabilities by incorporation of ring systems in the conjugated olefinic chain. 6 The use of cyclic groups as part of a conjugated olefinic chain has also been employed in color indicators $7 \mathrm{a}$ and NLO chromophores. ${ }^{7 b}$ However, there is no experimental data to demonstrate enhancement of thermal stability induced by the configuration-locked cyclic $\pi$-system. The chromophores were prepared by means of two consecutive Knoevenagel condensations. The first products, obtained by reacting isophorone with electronegative 
methylene compounds such as 3-phenyl-2-isoxazoline-5-one, 1,3-diethyl-2-thiobarbituric acid, and malononitrile, were then used for the second condensation with the corresponding aldehydes. We have recently developed a facile approach to synthesizing of 3-(4-diethylaminostyryl)-5,5-dimethyl-2-cyclohexen1-one 1a, which can then be condensed with a series of electronegative methylene compounds to form NLO chromophores with broad variations of electron acceptors. More significant is that the $\pi$-conjugated system can be extended from the carbonyl group of the dienone derivative via the Wittig-Horner condensation with 2-thiophenemethyl phosphonate to produce an efficient conjugation moiety with the combination of triene and thiophene ring. Following attachment of strong electron acceptors to the thiophene ring, NLO chromophores with considerably large nonlinearities were obtained.

A series of configuration-locked triene chromophores prepared in this study are shown in Scheme 1. Compound 1a was synthesized by Knoevenagel condensation of 4-diethylaminobenzaldehyde with isophorone in the presence of $\mathrm{tBuOK} / \mathrm{tBuOH}$ in $70 \%$ yield. The following successive Knoevenagel condensations of compound 1a with malononitrile and 1,3-diethyl-2-thiobarbituric acid yielded, respectively, compound 2a and 3a. Wittig-Horner condensation of compound 1a with 2-thiophenemethyl phosphonate in t-BuOK/THF gave compound 4a. Compound 4a, which does not have an electron-withdrawing group at the end of the conjugated moieties, was obtained as a mixture of trans-trans-trans and trans-trans-cis isomers with a ratio $2: 1$, as determined by ${ }^{1} \mathrm{H}$ NMR spectroscopy. Lithiation of compound 4a with $\mathrm{n}$-BuLi and subsequent quenching with dimethylformamide (DMF) resulted in aldehyde 5a. Condensation of aldehyde 5a with malononitrile and diethylthiobarbituric acid gave the corresponding compounds $6 \mathbf{a}$ and $7 \mathbf{a}$, respectively. Lithiation of compound $4 \mathrm{a}$ with $\mathrm{n}-\mathrm{BuLi}$ and followed by treatment of tetracyanoethylene (TCNE) led to the tricyanovinyl substituted chromophore 8a. All the double-bond linkages in these compounds except for 4 a were confirmed to be all-trans by careful NMR analysis. 8

\section{Scheme 1}
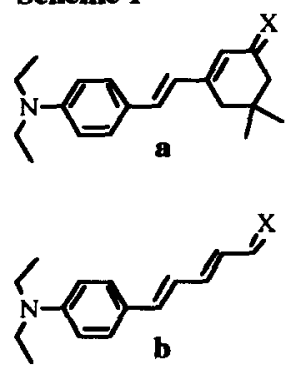

2a, 2b $x==_{\mathrm{CN}}^{\mathrm{CN}}$

3a, 3b $x==\sum_{O}^{O}=\mathrm{N}$

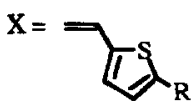

4a, 4b $R=H$

5a, $5 \mathbf{b} \quad \mathrm{R}=\mathrm{CHO}$

6a, 6b $\mathrm{R}=$<smiles>CC=C([Al])[W]</smiles>

7a, $7 \mathbf{b} \quad \mathbf{R}=$<smiles>C/C=C1/C(=O)N(CC)C(=S)N1CC</smiles>

$8 a, 8 b \quad R=\overbrace{C N}^{N}$
Table 1

\begin{tabular}{|c|c|c|c|}
\hline & $\overline{\lambda \max }$ & $\varepsilon /$ & \\
\hline compound & $\mathrm{nm}$ & $10^{4} \mathrm{M}^{-1} \mathrm{~cm}^{-1}$ & $T_{d}{ }^{b}$ \\
\hline $2 \mathbf{a}$ & 498 & 3.3 & 336 \\
\hline $\mathbf{2 b}$ & 508 & 4.7 & 251 \\
\hline $\mathbf{3 a}$ & 562 & 5.4 & 253 \\
\hline $\mathbf{3 b}$ & 580 & 4.4 & 212 \\
\hline $6 a$ & 558 & 4.4 & 267 \\
\hline $6 \mathbf{b}$ & 546 & 3.8 & 227 \\
\hline $7 \mathbf{a}$ & 608 & 5.4 & 225 \\
\hline $\mathbf{7 b}$ & 600 & 4.6 & 208 \\
\hline $8 a$ & 686 & 4.8 & 251 \\
\hline 86 & 678 & 4.7 & 198 \\
\hline
\end{tabular}

${ }^{\mathrm{a}}$ In dioxane. ${ }^{\mathrm{b}}$ In ${ }^{\circ} \mathrm{C}$. 
In order to compare thermal stabilities, simple trienes with all-trans geometry were also prepared. Starting with 5-(4-diethylaminophenyl)-2,4-pentadienal 1b, which was prepared from 2-(3diethylphosphono-1-propenyl)-1,3-dioxolane ${ }^{9}$ and $\mathrm{N}, \mathrm{N}$-diethylaminobenzaldehyde, and by utilizing the synthetic strategy for the preparation of the cyclic analogues, a series of NLO chromophores in which the $\pi$ conjugated hexatrienic moieties were not configuration-locked were prepared, as shown in Scheme 1.

Electronic absorption spectra of these compounds were obtained to compare their intramolecular charge-transfer properties (Table 1). The relative strengths of the acceptors for compounds in Table 1 are ranked as follows: tricyano vinyl > 1,3-diethylthiobarbituric acid > dicyano vinyl. As the strength of the acceptors increased, the charge-transfer (CT) band of these chromophores showed an expected progressive bathochromic shift. The addition of a thiophene ring into the $\pi$-conjugating system induced a pronounced red shift in the CT band, indicating the more efficient electron delocalization nature of the combination of triene and thiophene ring. When compared to the corresponding hexatrienic chromophores, the cyclic hexatrienic chromophores have a slight red-(or blue-)shifted CT band. This result suggests that incorporation of a 6-membered ring would not reduce the planarity and the electron delocalization efficiency of the $\pi$ conjugation system.

Thermal stabilities were estimated by differential scanning calorimetry (DSC, $10 \mathrm{deg} / \mathrm{min}$ ). The intercept of the leading edge of the thermal decomposition exotherm by the base line of each DSC scan was assigned as the decomposition temperature ( $T_{\mathrm{d}}$ ). Comparison of the $T_{\mathrm{d}}$ 's of cyclic hexatrienic NLO chromophores with those of the corresponding hexatrienic chromophores reveals that the configuration locking method provides a dramatic enhancement of molecular thermal stability. The origins of the thermal decomposition of the polyenic chromophores are currently being investigated. It was speculated that thermally induced cis-trans isomerization followed by decomposition was the source of thermal instability, 10 and that the cyclic-locked, all-trans geometry seems to be more stable to resist degradation mechanism that involving cis-trans isomerization.

Preliminary experiments indicated that the combination of the configuration-locked trans-triene bridge with the tricyanovinyl acceptor ${ }^{11}$ provides a very efficient mechanism for enhancing molecular nonlinearity. 12 The $\beta_{\text {of }} \mu$ value of compound $8 \mathrm{a}\left(5480 \times 10^{-48} \mathrm{esu}\right.$ ) was determined by an electric field induced second harmonic generation (EFISH) technique 13 using $1.907 \mu \mathrm{m}$ fundamental radiation and corrected for dispersion using the two-state model. 14 When $8 \mathrm{a}$ was doped (15 wt \%) in a polyquinoline (PQ-100) host and poled at $210{ }^{\circ} \mathrm{C}$ with a poling field of $1.4 \mathrm{MVcm}^{-1}$, the resulting polymer had an electrooptic coefficient, $\mathrm{r33}$, of $27 \mathrm{pmV}^{-1}$ measured at $1.3 \mu \mathrm{m}, 15$ consistent with the large nonlinearity.

In summary, we have developed a new and facile synthetic methodology for obtaining NLO chromophores with cyclic-locked all trans $\pi$-conjugating moieties possessing exceptionally large molecular nonlinearities and enhanced thermal stabilities. Experiments to incorporate these chromophores into high temperature polymers and to extend the synthetic approach to double annulated rings 16 are in progress.

Acknowledgment We thank the National Science Council (ROC) (NSC 84-2113-M-009-003) and the Office of Naval Research (N 00014-95-1-1319) for financial support.

\section{References and Notes}

1. (a) Chemical and Engineering News 1996, March 4, 22-27. (b) Dalton, L. R.; Harper, A. W.; Ghosn, R.; Steier, W. H.; Ziari, M.; Fetterman, H.; Shi, Y.; Mustacich, R. V.; Jen, A. K-Y.; Shea, K. J. Chem. Mater. 1995, 7, 1060-1081. 
2. Cheng, L.-T.; Tam, W.; Marder, S. R.; Stiegman, A. E.; Rikken, G.; Spangler, C. W. J. Phy. Chem. 1991, 95, 10643-10652.

3. Marder, S. R.; Beratan, D. N.; Cheng, L.-T. Science 1991, 252, 103-106.

4. Marder, S. R.; Cheng, L-T.; Tiemann, B. G.; Friedli, A. C.; Blanchare-Desce, M.; Perry, J. W.; Skindhoj, J. Science 1994, 263, 511-514.

5. (a) Moylan, C. R.; Twieg, R. J.; Lee, V. Y.; Swanson, S. A.; Betterton, K. M.; Miller, R. D. J. Am. Chem. Soc. 1993, 115, 12599-12600. (b) Gilmour, S.; Marder, S. R.; Perry, J. W.; Cheng, L.-T. Adv. Mater. 1994, 6, 494-496. (c) Gilmour, S.; Montgomery, R. A.; Marder, S. R.; Cheng, L.-P.; Jen, A. Y.-K. Cai, Y.; Perry, J. W.; Dalton, L. R. Chem. Mater. 1994, 6, 1603-1604.

6. (a) Reynolds, G. A.; Drexhage, K. H. J. Org. Chem. 1977, 42, 885-888. (b) Raue, R.; harnisch, H.; Drexhage, K. H. Heterocycles, 1984, 21, 167-190.

7. (a) Brooker, L. G. S.; Craig, A. C.; Heseltine, D. W.; Jenkins, P. W.; Lincoln, L. L. J. Am. Chem. Soc. 1965, 87, 2443-2450. (b) Man, H. T.; Shu, C.-F.; Althoff, O.; McCulloch, 1. A.; Pollis, D.; Yoon, H. N. J. Appl. Polym. Sci. 1994, 53, 641-647.

8. ${ }^{\mathrm{H}}$-NMR spectra were recorded on a Varian Unity $300 \mathrm{MHz}$ spectrometer with TMS as internal standard, $\mathrm{CDCl}_{3}$ as solvent. Chemical shifts are in ppm, coupling constants are in $\mathrm{Hz}$. $1 \mathrm{a}: \delta 1.07(\mathrm{~s}, 6 \mathrm{H}), 1.15(\mathrm{t}, 6 \mathrm{H}, \mathrm{J}$ = 6.9), $2.26(\mathrm{~s}, 2 \mathrm{H}), 2.43(\mathrm{~s}, 2 \mathrm{H}), 3.39(\mathrm{q}, 4 \mathrm{H}, \mathrm{J}=6.9), 6.00(\mathrm{~s}, 1 \mathrm{H}), 6.64(\mathrm{~d}, 2 \mathrm{H}, \mathrm{J}=8.7), 6.70(\mathrm{~d}, 1 \mathrm{H}, \mathrm{J}=$ 16.2), $6.93(\mathrm{~d}, 1 \mathrm{H}, \mathrm{J}=16.2$ ), 7.37 (d, $2 \mathrm{H}, \mathrm{J}=8.7$ ). $2 \mathrm{a}: \delta 1.06(\mathrm{~s}, 6 \mathrm{H}), 1.21(\mathrm{t}, 6 \mathrm{H}, \mathrm{J}=6.9), 2.45(\mathrm{~s}, 2 \mathrm{H}), 2.56$ (s, 2H), $3.42(\mathrm{q}, 4 \mathrm{H}, \mathrm{J}=6.9), 6.65(\mathrm{~d}, 2 \mathrm{H}, \mathrm{J}=8.7), 6.74(\mathrm{~s}, 1 \mathrm{H}), 6.78(\mathrm{~d}, 1 \mathrm{H}, \mathrm{J}=16.2), 7.02(\mathrm{~d}, 1 \mathrm{H}, \mathrm{J}=16.2)$, $7.39(\mathrm{~d}, 2 \mathrm{H}, \mathrm{J}=8.7) .3 \mathrm{a}: \delta 1.06(\mathrm{~s}, 6 \mathrm{H}), 1.21(\mathrm{t}, 6 \mathrm{H}, \mathrm{J}=6.9), 1.31(\mathrm{~m}, 6 \mathrm{H}), 2.42(\mathrm{~s}, 2 \mathrm{H}), 3.11(\mathrm{~s}, 2 \mathrm{H}), 3.42$ (q, 4H, J = 6.9), $4.55(\mathrm{~m}, 4 \mathrm{H}), 6.65(\mathrm{~d}, 2 \mathrm{H}, \mathrm{J}=8.7), 6.97(\mathrm{~d}, 1 \mathrm{H}, \mathrm{J}=16.2), 7.10(\mathrm{~d}, 1 \mathrm{H}, \mathrm{J}=16.2), 7.42(\mathrm{~d}, 2 \mathrm{H}$, $\mathrm{J}=8.7), 8.41(\mathrm{~s}, \mathrm{lH}) .6 \mathrm{a}: \delta 1.06(\mathrm{~s}, 6 \mathrm{H}), 1.18(\mathrm{t}, 6 \mathrm{H}, \mathrm{J}=6.9), 2.30(\mathrm{~s}, 2 \mathrm{H}), 2.51(\mathrm{~s}, 2 \mathrm{H}), 3.38(\mathrm{q}, 4 \mathrm{H}, \mathrm{J}=6.9)$, $6.27(\mathrm{~s}, 1 \mathrm{H}), 6.60(\mathrm{~s}, 1 \mathrm{H}), 6.64(\mathrm{~d}, 2 \mathrm{H}, \mathrm{J}=9.0), 6.66(\mathrm{~d}, 1 \mathrm{H}, \mathrm{J}=15.9), 6.71(\mathrm{~d}, 1 \mathrm{H}, \mathrm{J}=15.9), 7.07(\mathrm{~d}, 1 \mathrm{H}, \mathrm{J}=$ 4.2), $7.34(\mathrm{~d}, 2 \mathrm{H}, \mathrm{J}=9.0), 7.66(\mathrm{~d}, 1 \mathrm{H}, \mathrm{J}=4.2), 7.67(\mathrm{~s}, 1 \mathrm{H}) .7 \mathrm{a}: \delta 1.10(\mathrm{~s}, 6 \mathrm{H}), 1.19(\mathrm{t}, 6 \mathrm{H}, \mathrm{J}=6.9), 1.33(\mathrm{~m}$, 6H), $2.33(\mathrm{~s}, 2 \mathrm{H}), 2.64(\mathrm{~s}, 2 \mathrm{H}), 3.39(\mathrm{q}, 4 \mathrm{H}, \mathrm{J}=6.9), 4.61(\mathrm{~m}, 4 \mathrm{H}), 6.32(\mathrm{~s}, 1 \mathrm{H}), 6.63(\mathrm{~s}, 1 \mathrm{H}), 6.64(\mathrm{~d}, 2 \mathrm{H}, \mathrm{J}=$ 8.7), $6.69(\mathrm{~d}, 1 \mathrm{H}, \mathrm{J}=16.2), 6.75(\mathrm{~d}, 1 \mathrm{H}, \mathrm{J}=16.2), 7.20(\mathrm{~d}, 1 \mathrm{H}, \mathrm{J}=4.5), 7.34(\mathrm{~d}, 2 \mathrm{H}, \mathrm{J}=8.7), 7.83(\mathrm{~d}, 1 \mathrm{H}, \mathrm{J}=$ 4.5), $8.58(\mathrm{~s}, 1 \mathrm{H}) .8 \mathrm{a}: \delta 1.08(\mathrm{~s}, 6 \mathrm{H}), 1.19(\mathrm{t}, 6 \mathrm{H}, \mathrm{J}=6.9), 2.35(\mathrm{~s}, 2 \mathrm{H}), 2.54(\mathrm{~s}, 2 \mathrm{H}), 3.40(\mathrm{q}, 4 \mathrm{H}, \mathrm{J}=6.9$ ), $6.32(\mathrm{~s}, 1 \mathrm{H}), 6.62(\mathrm{~d}, 2 \mathrm{H}, \mathrm{J}=8.7), 6.63(\mathrm{~s}, 1 \mathrm{H}), 6.73(\mathrm{~s}, 2 \mathrm{H}), 7.11(\mathrm{~d}, 1 \mathrm{H}, \mathrm{J}=4.8), 7.34(\mathrm{~d}, 2 \mathrm{H}, \mathrm{J}=8.7), 7.94$ (d, $1 \mathrm{H}, \mathrm{J}=4.8$ ).

9. Duhamel, L.; Guillemont, J.; Gallic, Y. L.; Ple, G.; Poirier, J.-M.; Ramondenc, Y.; Chabardes, P. Tetrahedron Lett. 1990, 31,3129-3132.

10. Rao, V. P.; Cai, Y. M.; Jen, A, K.-Y. J. Chem. Soc., Chem. Commun. 1994, 1689-1690.

11. Rao, V. P.; Jen, A, K.-Y.; Wang, K. Y. Drost, K. J. J. Chem. Soc., Chem. Commun. 1993, 1118-1120.

12. Shu, C.-F.; Tsai, W.-T.; Chem, J.-Y.; Jen, A. K.-Y.; Zhang. Y. Chem. T.-A. submitted for publication.

13. Wong, K. Y.; Jen, A. K-Y.; Rao, V. P. Phys. Rev. A. 1994, 49, 3077-3080.

14. Oudar, J. L.; Chemla, D. S. J. Chem. Phys. 1977, 66, 2664-2668.

15. Teng, C. C.; Man, H. H. Appl. Phys. Lett. 1990, 56, 1734-1736.

16. Cabrera, I.; Althoff, O.; Man, H. T.; Yoon, H. N. Adv. Mater. 1994, 6, 43-45.

(Received in Japan 15 June 1996; revised 30 July 1996; accepted 6 August 1996) 